\title{
IR Remote Control and Eye Blink Sensor based Implementation of Driver Drowsiness Detection
}

\author{
Pankti P. Bhatt, Jeegar A. Trivedi
}

\begin{abstract}
Street mishaps are a typical marvel in our everyday lives. Every year these street mishaps prompted numerous passings, deadly wounds and monetary misfortunes everywhere throughout the world. India positions first in the number of street mishap passings over the 199 nations announced in the World Road Statistics, 2018 followed by China and the USA. According to the WHO Global Report on Road Safety 2018, India represents practically $11 \%$ of the mishap related passings in the World. One of the major reasons for these mishaps is the sleepiness of drivers. Accordingly, it is important to build up a strategy to recognize the driver's laziness to decrease the mishap rates. In this paper, we have proposed a recognizing, avoidance and alerting system to minimize the street mishaps which are causing due to the sleepiness of drivers using Arduino Microcontroller, Eye Blink Sensor, IR Remote Control and IR Remote Receive Module.
\end{abstract}

Keywords : 4WD Robot, Arduino Microcontroller, Buzzer, Driver Drowsiness Detection, Eye Blink Sensor, IR Remote Control, IR Remote Receive.

\section{INTRODUCTION}

As of late, sluggishness or drowsiness has been credited as a significant contributory factor to all the significant car crashes [1]. "Drowsy State" is a condition of powerful urge for rest or may cause because of disease [2]. The improvement of developments for recognizing or on the other hand turning away languor in the driver's seat is a significant test in the field of mishap shirking frameworks. In perspective on the hazard that Drowsiness display all over the place, techniques ought to be made for killing its belongings [3]. For defeating these arrangements of issues numerous scientists have created different arrangements which are explicit to its motivation [4]. This thought is structured dependent on Arduino Microcontroller board and aides in controlling street mishaps because of obviousness through sensors [5]. The latest technology helps to recognize and avoid the street mishaps to some level [6].

This paper implements technique to reduce the street mishaps by using hardware tools such as IR Remote Control, IR Remote Receiver Module, Eye Blink Sensor, 4WD Robot, Buzzer and Arduino Microcontroller as its main components.

Revised Manuscript Received on February 25, 2020.

* Correspondence Author

Pankti P. Bhatt*, G. H. Patel PG Department of Computer Science and Technology, Sardar Patel University, Vallabh Vidyanagar, Gujarat, India. Email: bhatt_011089@yahoo.com

Dr. Jeegar A. Trivedi, G. H. Patel PG Department of Computer Science and Technology, Sardar Patel University, Vallabh Vidyanagar, Gujarat, India. Email: jeegartrivedi@yahoo.com

(C) The Authors. Published by Blue Eyes Intelligence Engineering and Sciences Publication (BEIESP). This is an open access article under the CC BY-NC-ND license (http://creativecommons.org/licenses/by-nc-nd/4.0/)
In this manner, this framework gives wellbeing and careful steps which can be implemented on vehicles in parkways for decreasing casualty rate and has the accompanying bit of leeway for example to diminish death rate and to build security levels of the vehicle[7].

\section{ARCHITECTURE OF THE SYSTEM}

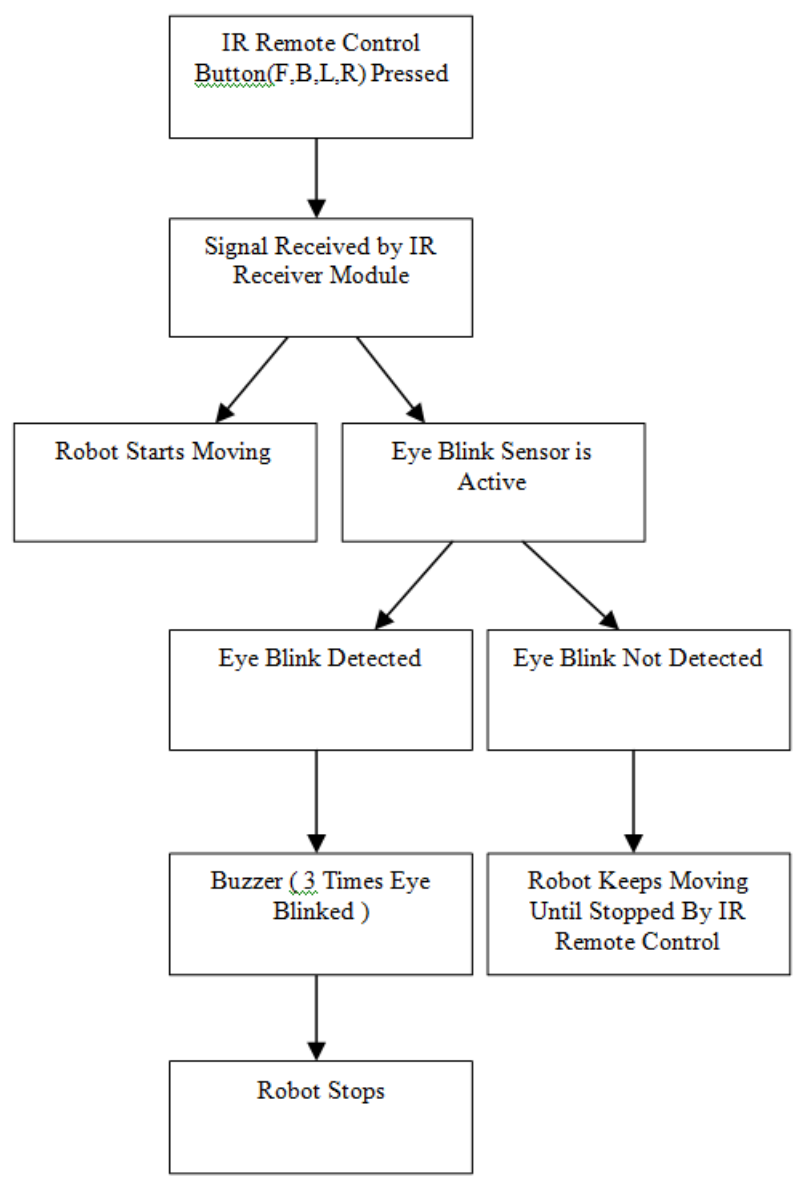

Fig. 1. Architecture of the System

\section{WORKING PRINCIPLE}

The Driver Drowsiness Detection uses Eye Blink Sensor, IR Remote Control and IR Remote Receiver Module for its advancements. An Arduino Microcontroller is used to achieve the pined for task. The 4WD motors are related through a motor driver IC microcontroller. The 4WD robot starts moving in forward direction on forward button press by the IR Remote Control. The signal from the IR Remote Control is transmitted and captured by the IR Remote Receiver Module.

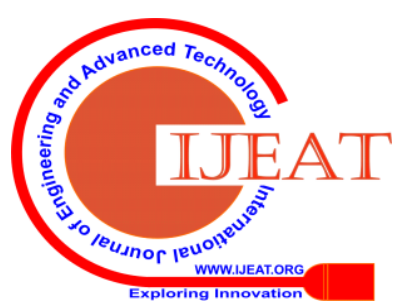


Meanwhile the Eye Blink Sensor activates and looks for any blinking of eye. If eye blinks three times then the motor stops and driver is alerted by ringing buzzer. If eye doesn't blink then the 4WD robot continues moving. The programming is done in Arduino software IDE

\section{SCREENS}

\section{A. Eye Blink Sensor}

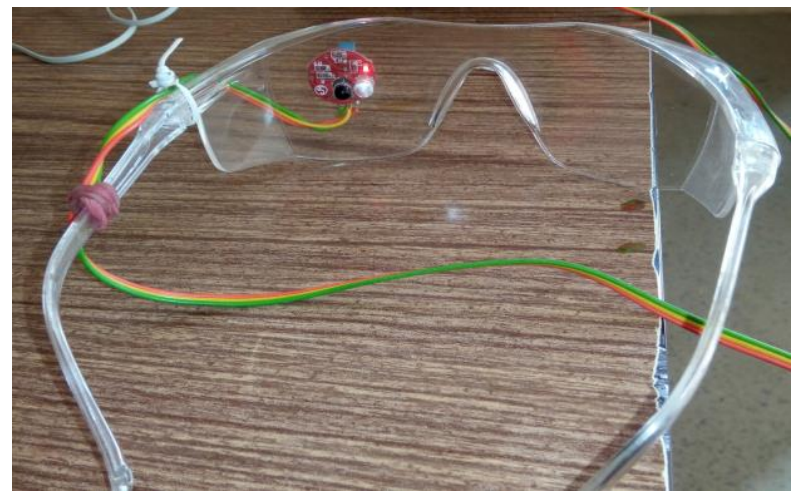

Fig. 2. Eye Blink Sensor is active

\section{B. IR Remote Receiver}

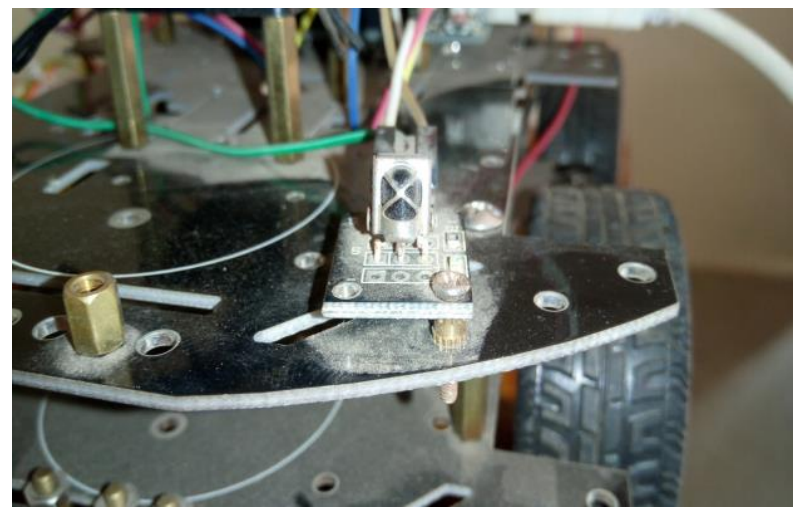

Fig. 3. IR Remote Receiver Module

\section{IR Remote Controller \& IR Receiver}

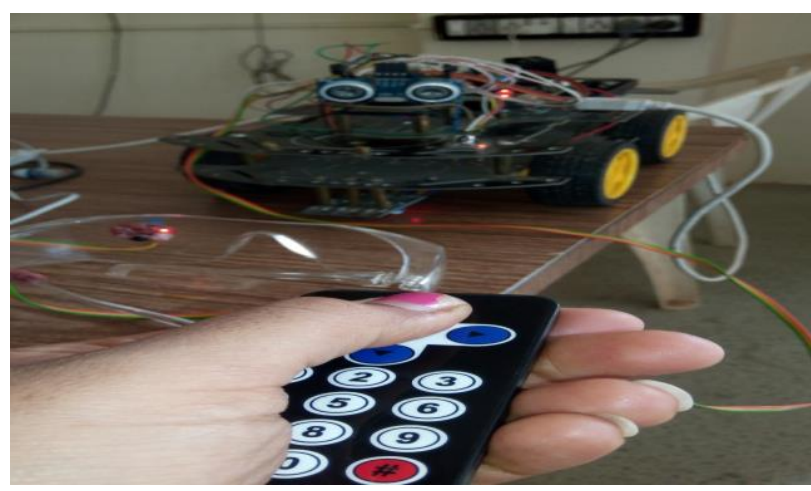

Fig. 4. IR Remote Controller \& IR Receiving Module receiving Signal

\section{Buzzer}

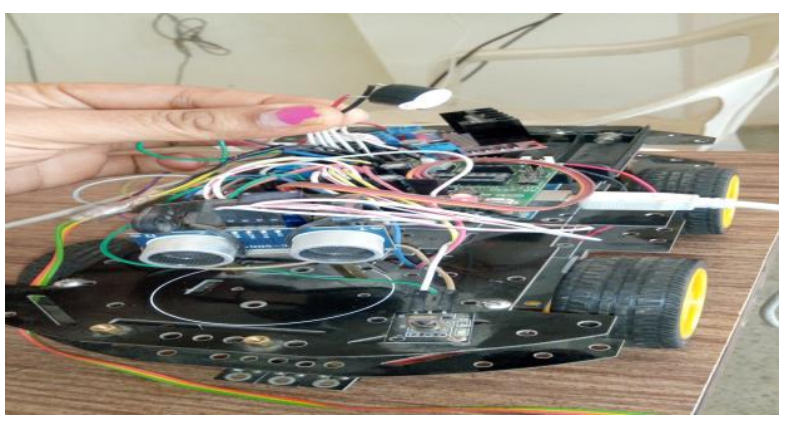

Fig. 5. Buzzer

\section{RESULTS}

In IR Remote control there are total 4 buttons used i.e. forward, backward, left and right. Firstly, to make the robot run in forward direction, forward button is pressed. As the forward button is pressed, the signal from the IR remote control is received by the IR Receiver Module. As the IR Receiver Module receives the signal it directs through the Arduino microcontroller and makes the 4WD robot move in forward direction. Meanwhile it also activates the Eye blink sensor. Eye Blink Sensor searches for any blinking of the eye. The continuous sensor data value is appending. If the sensor data value comes less than 150 threshold value then the Eye Blink Sensor detects Eye Blink else it appends any arbitrary data value. In Figure 6 it shows that if Eye Blink Sensor finds eye blinking three times than the driver is alarmed by the buzzer ringing three times and the 4WD robot stops moving. In Figure 7 it shows that Eye Blink Sensor does not find any eye blinking and the 4WD robot keeps on moving until any another button is pressed from the IR Remote Control, Also the continuous Sensor Value can be seen.

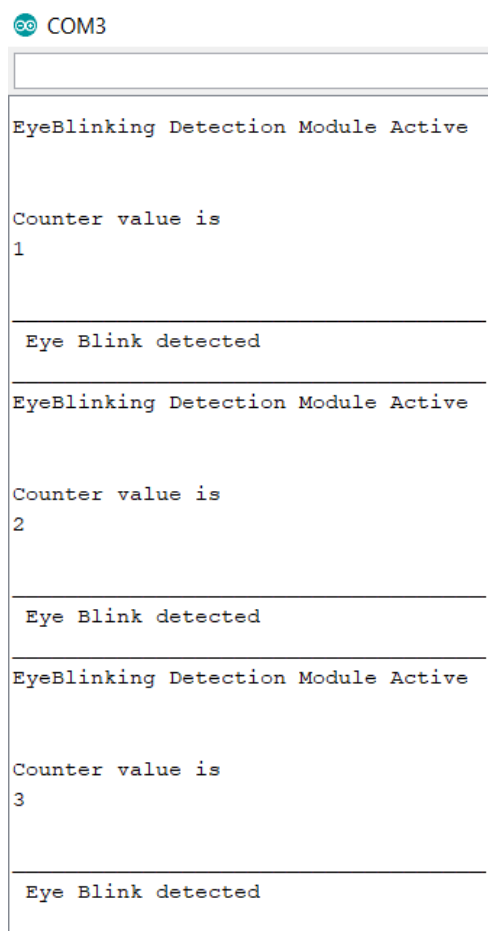

Fig. 6. Eye Blink Detected 


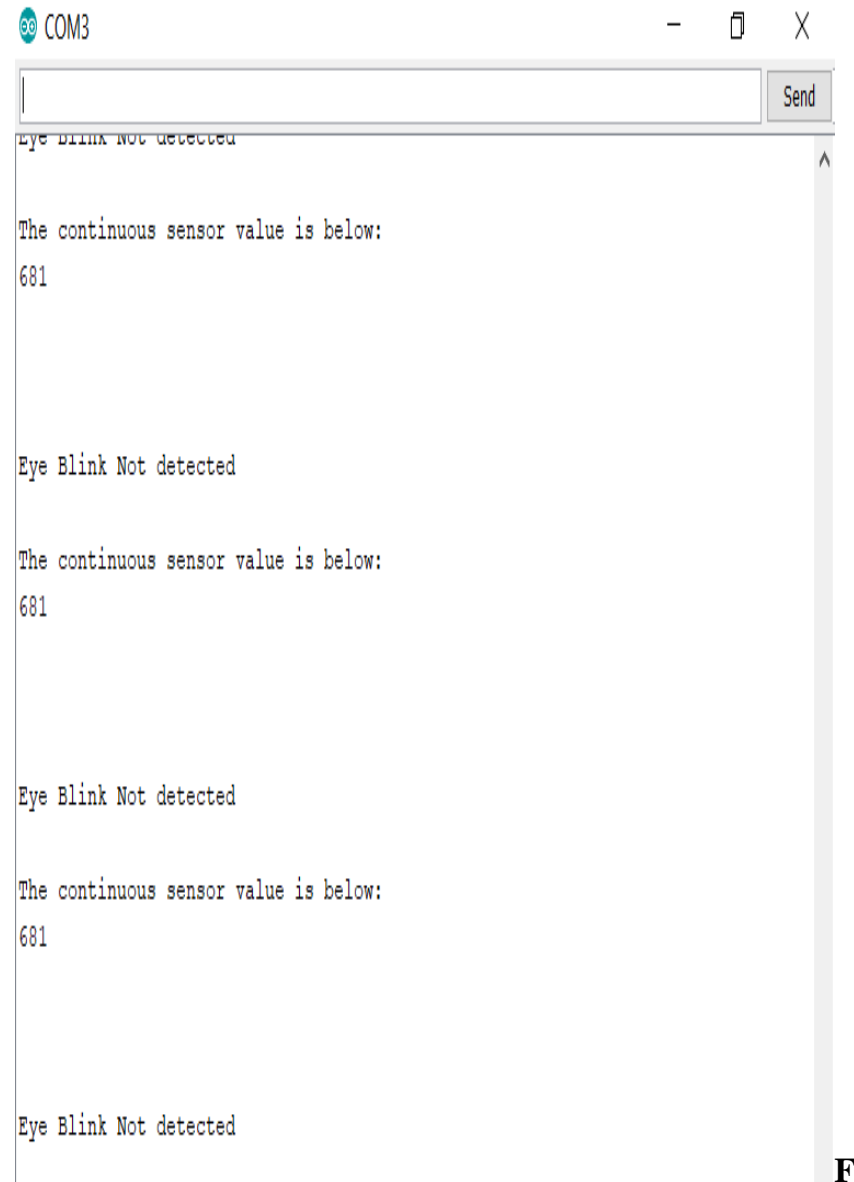

ig. 7. Eye Blink Not Detected

\section{CONCLUSION}

Monitoring and recognizing the mishaps play a definitive job in forestalling or limiting the quantity of vehicle mishaps. In this paper we have proposed a low cost, adaptable, qualitative, user safety and security system. This work presents structure of a lower power implanted framework. Furthermore, it is blended with sensors to forestall the street mishaps.

\section{REFERENCES}

1. O. Sinha, S. Singh, A. Mitra, S. K. Ghosh, S. Raha, "Development of a Drowsy Driver Detection System Based on EEG and IR-based Eye Blink Detection Analysis", (C) Springer Nature Singapore Pte Ltd. 2018, pp. 313-319.

2. C. Sandeep, C. Mounica, N. M. Reddy, M. Pradhyumna, "IMPLEMENTATION OF DRIVER DROWSINESS ALERT AND AUTOMATIC VEHICLE CONTROL SYSTEM USING ARDUINO”, International Journal of Advance Engineering and Research Development Volume 5, Issue 03, March -2018, pp. 1616-1623.

3. M. Shashidhara, C. N. Shruthi, R. J. Karanraj, S. Vignesh, R. D. Anitha Kumari, "SMART CAR FOR DRIVER ALERT", International Journal of Advanced Research in Science and Engineering, Volume No.07, Special Issue No.07, April 2018, pp. 440-445.

4. Dr.S. S. Nath, T. Archana, "Safer Drive using Sensing and Alerting Techniques", International Journal of Pure and Applied Mathematics, Volume 119, Special Issue No. 15, 2018, pp. 2055-2063.

5. G. K. Bhavani, S. Reddy, "Vehicle Accident Prevention Using Sensors", International Journal of Computer \& Mathematical Sciences, Volume 7, Issue 2, February 2018, pp. 338-342.

6. S. S. CHALWAD, S. B. GAIKWAD, P. A. CHOUGULE, "ACCIDENT PREVENTION USING EYE BLINK SENSOR”, International Journal of Advances in Electronics and Computer Science, Volume-4, Issue-1, Jan.-2017, pp. 79-81.

7. Prof. C. Gosal, A. Chadaga. P, A. Balraj. R, K. M. Madhu Kiran, T. M. Manoj, "Intelligent Automatic Vehicle Accident Detection and
Prevention System", Journal of Engineering Research and Application, Vol. 7, Issue 7 (Part -2), July 2017, pp.37-41.

\section{AUTHORS PROFILE}

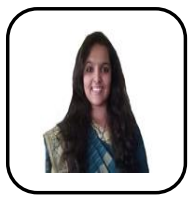

Pankti P. Bhatt pursued Bachelor of Computer Application from Sardar Patel University, Vallabh Vidyanagar Gujarat, India in 2010 and Master of Computer Application from Gujarat Technological University, Gujarat, India in 2013. She is currently pursuing Ph.D. in G. H. Patel PG Department of Computer Science \& Technology, Sardar Patel University, Gujarat, India. Her main research work focuses on Artificial Intelligence, Embedded Systems.

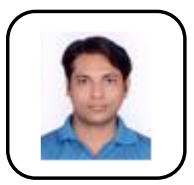

Dr. Jeegar A. Trivedi pursued Masters in Computer Applications degree from the Sardar Patel University, Vallabh Vidyanagar, Gujarat, India, in 2010, and the Ph.D.degree from Sardar Patel University in 2013. He is currently an Assistant Professor in the Department of Computer Science, Sardar Patel University. His research interests include neuro-fuzzy systems, type-2 fuzzy systems, and wireless networks. He is the author of many refereed publications in international journals, book chapters, and conference proceedings. He has chaired national and international conferences in his research domain. He has also served as a resource person to many national and international institutes. 